\title{
Mutation of a Short Variable Region in HCpro Protein of Potato virus A Affects Interactions with a Microtubule-Associated Protein and Induces Necrotic Responses in Tobacco
}

\author{
Tuuli Haikonen, Minna-Liisa Rajamäki, Yan-Ping Tian, and Jari P. T. Valkonen \\ Department of Agricultural Sciences, P.O. Box 27, FI-00014 University of Helsinki, Finland \\ Submitted 22 January 2013. Accepted 5 March 2013.
}

\begin{abstract}
Helper component proteinase (HCpro) is a multifunctional protein of potyviruses (genus Potyvirus). HCpro of Potato virus $A$ (PVA) interacts with the microtubule-associated protein HIP2 in host cells, and depletion of HIP2 reduces virus accumulation. This study shows that HCpro of Potato virus $Y$ and Tobacco etch virus also interact with HIP2. The C-proximal portion of PVA HCpro determines the interaction with HIP2 and was found to contain a stretch of six residues comprising a highly variable region (HVR) in potyviruses. Mutations in HVR reduced PVA accumulation in tobacco plants and induced necrotic symptoms novel to PVA. Microarray and quantitative reverse transcription polymerase chain reaction analyses revealed induction of many defense-related genes including ethylene- and jasmonic acid-inducible pathways in systemically infected leaves at necrosis onset. Salicylic acid-mediated signaling was dispensable for the response. Genes related to microtubule functions were downregulated. Structural modeling of HCpro suggested that all mutations in HVR caused conformational changes in adjacent regions containing functionally important motifs conserved in potyviruses. Those mutations, which also caused conformational changes in HVR, led to the greatest reduction of fitness. Our results implicate HVR in the regulation of HCpro conformation and virus-host interactions and suggest that mutation of HVR induces host defense.
\end{abstract}

The helper component proteinase (HCpro) encoded by potyviruses (genus Potyvirus, family Potyviridae) is a multifunctional protein involved in many steps of the viral infection cycle. It is needed for virus accumulation and movement, suppression of RNA silencing-based antiviral defense, and transmission of the virus by aphid vectors (Rajamäki et al. 2004). HCpro forms homodimers, tetramers, hexamers, and persistent aggregates (inclusions) in plant cells (Guo et al. 1999; Plisson et al. 2003; Purcifull and Hiebert 1992; Ruiz-Ferrer et al. 2005). Based on structural predictions, HCpro comprises three main regions (Plisson et al. 2003), namely the $\mathrm{N}$ - and C-terminal regions, each covering approximately 100 amino acid resi-

Corresponding author: J. P. T. Valkonen; Telephone: +358-9-19158387; Fax: +358-9-19158727; E-mail: jari.valkonen@ @elsinki.fi

* The $\boldsymbol{e}$-Xtra logo stands for "electronic extra" and indicates that six supplementary figures and one supplementary table are published online.

(C) 2013 The American Phytopathological Society dues, and the central region that covers approximately 250 residues and includes a 'hinge' domain (approximately 100 residues) connecting the central and $\mathrm{C}$-terminal regions (Guo et al. 2011; Plisson et al. 2003) (Fig. 1A). Structural analysis of HCpro has proven challenging with biochemical methods, and only the C-terminal cysteine proteinase domain has been resolved in Turnip mosaic virus (TuMV) (Guo et al. 2011). Lower-resolution structures are available for HCpro of Lettuce mosaic virus and Tobacco etch virus (TEV) (Plisson et al. 2003; Ruiz-Ferrer et al. 2005).

The N-terminal region of HCpro is required for virus transmission by vectors (Dolja et al. 1993). The C-terminal region comprises cysteine proteinase activity that cleaves the viral polyprotein at the C-terminal end of HCpro and releases HCpro from the polyprotein (Carrington et al. 1989). However, most functions of HCpro are conferred by the central region. Nonspecific RNA binding, virus movement, and viral amplification are associated with the conserved FRNK box (HCpro residues 181 to 184 in Potato virus $A$ [PVA]). The RNP-2 motif (LAIGNL box, residues 248 to 253) and another RNAbinding motif, RNP-1 (residues 284 to 291), and the CCC motif (residues 292 to 294) associated with long-distance movement in host plants are in the hinge domain (Cronin et al. 1995; Kasschau et al. 1997; Urcuqui-Inchima et al. 2000) that contains also the motif PTK (residues 310 to 312), which is needed for aphid transmissibility (Peng et al. 1998). Interaction of HCpro with the translation initiation factors eIF4E and eIF(iso)4E occurs via a conserved binding motif (4EBD, residues 345 to 351) (Ala-Poikela et al. 2011). RNA silencing suppression functions of HCpro are not restricted to any particular region of HCpro (Kasschau and Carrington 2001; Torres-Barceló et al. 2008).

The microtubule (MT)-associated proteins StHIP2 of potato (Solanum tuberosum L.) (Guo et al. 2003) and NtHIP2 of tobacco (Nicotiana tabacum L.) interact with PVA HCpro in PVA-infected plant cells (Haikonen et al. 2013). These proteins are homologous to the MT-associated proteins SPR2/TOR1 and SP2L of A. thaliana (Buschmann et al. 2004; Shoji et al. 2004; Yao et al. 2008). Bimolecular fluorescence complementation (BiFC) analysis in planta shows that interactions of HCpro with StHIP2 and NtHIP2 occur along MT, especially at MT junctions, and are determined by the C-proximal part of HIP2 (Haikonen et al. 2013). However, the region of HCpro controlling interactions with HIP2 is not known. Silencing of the two HIP2 homologs in Nicotiana benthamiana (98\% identical to $N t H I P 2)$ to an extent sufficient to induce the spiral growth phenotype similar to the spr2 knockout phenotype in Arabi- 
dopsis (Yao et al. 2008) reduces PVA accumulation in the inoculated tissues and causes delayed systemic infection with PVA (Haikonen et al. 2013). The aim of this study was to define the HCpro region required for HIP2 interaction and to further elucidate the biological role of HCpro-HIP2 interactions in PVA infection using mutagenesis of HCpro.

\section{RESULTS}

The C-terminal region of HCpro controls interactions with HIP2.

Secondary structures of PVA HCpro were predicted using the NPS@ server (Combet et al. 2000), and truncated forms were designed according to the structural model (Fig. 1A) to avoid disruption of putative functional domains (Plisson et al. 2003). The truncated forms of HCpro were tested for interactions with StHIP2 and NtHIP2 using the yeast two-hybrid system (YTHS), which revealed that the truncated proteins $(\Delta 3, \Delta 4, \Delta 5$, and $\Delta 6)$ containing the $\mathrm{C}$-terminal residues 325 to 458 of HCpro showed interactions with both HIP2 proteins (Fig. 1B). Internal deletions in HCpro (constructs $\Delta 14$ and $\Delta 15$ ) indicated that the interaction required residues 325 to 354 of HCpro (Fig. 1B). Expression of all proteins in yeast was detected with Western blotting (Supplementary Fig. 1; Ala-Poikela et al. 2011).

The PVA strains B11 (PVA-B11) and U (PVA-U) are biologically, serologically, and phylogenetically distinct (Andrejeva et al. 1999; Rajamäki et al. 1998; Valkonen et al. 1995). The HCpro proteins of PVA-B11 and PVA-U differ at residues 88, 89, 153, 330, and 437 (Rajamäki et al. 1998), of which residues 330 (Ala in PVA-B11, Thr in PVA-U) and 437 (Ile in PVA-B11,
Val in PVA-U) are in the C-terminal region that is important for HCpro-HIP2 interactions. Interaction of StHIP2 with U-HCpro was weaker than the interaction with B11-HCpro ( $t$ test, $P=$ 0.011) (Fig. 2B). Also the C-proximal parts ( $\Delta 4$ [230 to 458$]$ ) of both HCpro proteins interacted with StHIP2 (Fig. 2B). These results provided further evidence that the $\mathrm{C}$-proximal portion of HCpro controls interactions with HIP2.

Comparison of the HCpro sequences of 47 potyvirus species (Supplementary Fig. 2) showed that residue 330 of PVA HCpro is part of a stretch of six residues (330 to 335; Fig. 2A) comprising a highly variable region (HVR). All HVR residues in PVA differ from those in Pea seed-borne mosaic virus (PSbMV) (Fig. 2A), whose HCpro, unlike the HCpro of PVA, Potato virus $Y$ (PVY), and TEV, does not interact with StHIP2 and NtHIP2 (Supplementary Fig. 3). To convert it to a PSbMV-like form, four mutants of B11-HCpro were made: substitution of a single residue (A330K; mutant $\mathrm{HCmA})$, four residues $(\mathrm{HCmB})$, three residues $(\mathrm{HCmC})$, or all residues (HCmABC) of HVR (Fig. 2C). All mutants showed self-interaction in YTHS, as expected. HCmA and $\mathrm{HCmC}$ had somewhat reduced interaction with StHIP2 and NtHIP2, whereas interactions of $\mathrm{HCmB}$ with the HIP2 proteins were clearly reduced. No interaction was detected between $\mathrm{HCmABC}$ and the HIP2 proteins (Fig. 2C). These results suggested that HVR regulates HCpro-HIP2 interactions.

\section{Mutations in HVR reduce virus accumulation.}

The amino acid substitutions corresponding to $\mathrm{HCmA}$, $\mathrm{HCmB}$, and $\mathrm{HCmC}$ were introduced into the infectious clone of PVA-B11 (wtPVA), and the mutant clones PVAmA, PVAmB,

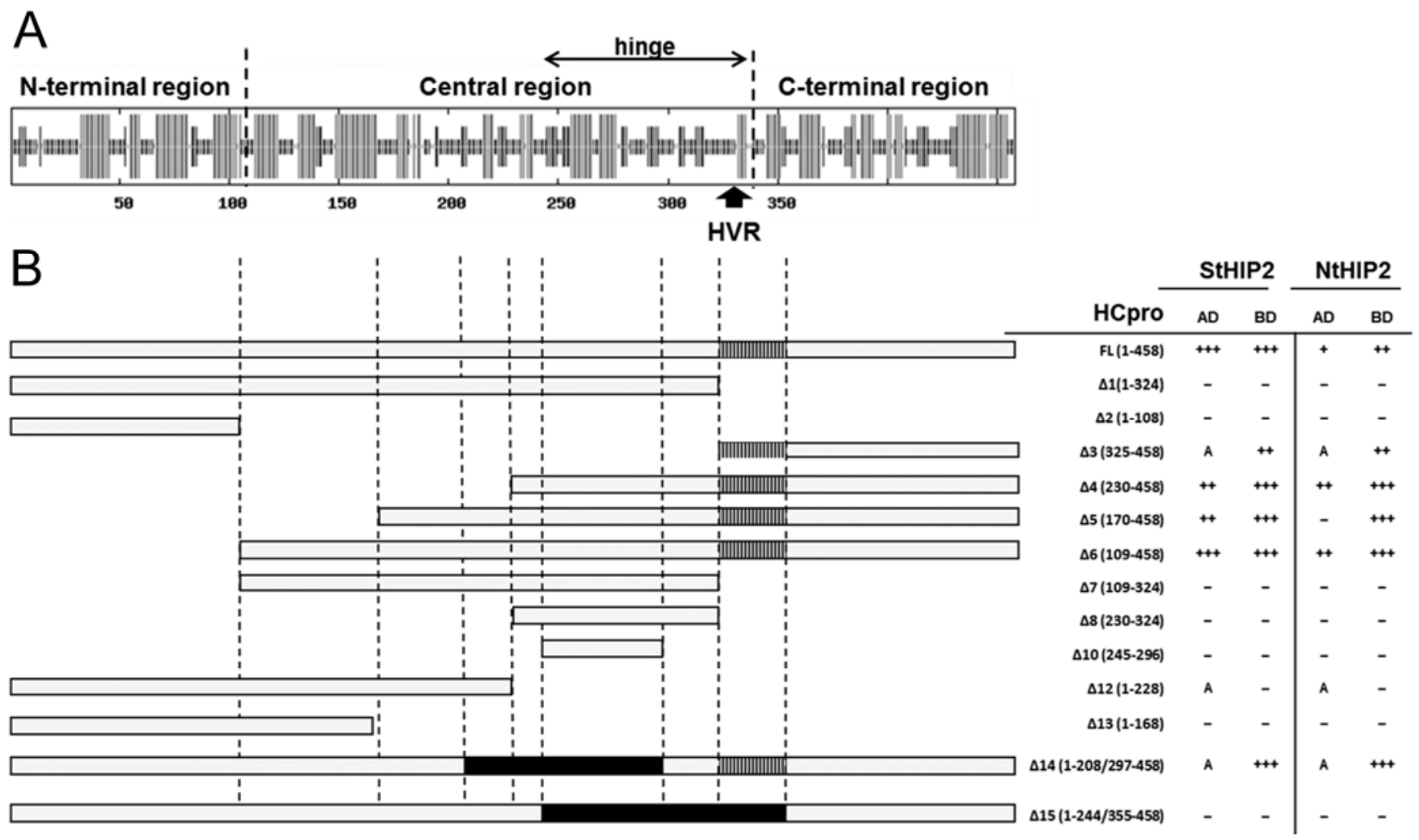

Fig. 1. The region of helper component proteinase (HCpro) in Potato virus A (PVA) conferring interactions with HIP2. A, Regions of HCpro according to Plisson and associates (2003) and Guo and associates (2011). The 'hinge' domain is included in the central region. The secondary structures of PVA HCpro were predicted using the NPS@ server and include $\alpha$-helices (tallest bars) and $\beta$-strands (middle-sized bars). Position of the the six-residue highly variable region (HVR) is indicated. B, Full-length (FL) PVA HCpro and 13 truncated forms were tested for interaction with StHIP2 (potato) and NtHIP2 (tobacco) in a yeast two-hybrid system. Growth of co-transformed yeast on selective medium: strong (+++), moderate (++), weak (+), or no growth (-) as observed 14 days after plating. The region (residues 325 to 354 ) critical for HCpro-HIP2 interaction is striped. Black-shaded regions in $\Delta 14$ and $\Delta 15$ indicate deleted internal parts of the protein. $\mathrm{AD}$ and $\mathrm{BD}$ indicate expression of the protein in fusion with the yeast transcription activation domain and binding domain, respectively. 
and PVAmC, respectively, and wtPVA were transferred to binary vectors. They were introduced into the leaves of tobacco cv. Samsun nn and $N$. benthamiana by agroinfiltration (agroinoculation) in two independent experiments to achieve simultaneous infection of a large number of cells and to eliminate possible differences in cell-to-cell movement of the viruses as a factor influencing virus accumulation. Pair-wise comparisons of the mutants with wtPVA were facilitated by infiltrating wtPVA and a mutant into opposite sides of the midrib in the same leaf. Titers of mutant viruses were only 24 to $55 \%$ and 55 to $85 \%$ of those of wtPVA in the leaf tissue of $N$. benthamiana and tobacco, respectively, 3.5 days postinfiltration. Differences were significant (Table 1). Virus titers of PVAmB tended to be reduced more than those of PVAmA and PVAmC. The use of Agrobacterium cultures with an optical density at $600 \mathrm{~nm}\left(\mathrm{OD}_{600}\right)=0.3$ or 0.6 resulted in similar relative differences in virus titers. A replication-deficient PVA genome achieved by mutation $\mathrm{Y} 63 \mathrm{~F}$ in the viral genome-linked protein (Germundsson et al. 2007) was included as a negative control in the experiments and showed no detectable accumulation of PVA coat protein $(\mathrm{CP})$ antigen.

The binary vectors containing PVAmA, PVAmB, PVAmC, and wtPVA were inoculated to $N$. benthamiana using particle bombardment (Sikorskaite et al. 2010), and all viruses infected the plants systemically (Table 2). The titers of PVAmA and PVAmC in the systemically infected leaves were initially low at 7 days postinoculation (dpi) but reached the titers of wtPVA by $14 \mathrm{dpi}$, in contrast to PVAmB whose titers remained low at all times in two independent experiments (Table 2). Analysis with immunocapture reverse transcription-polymerase chain reaction (IC-RT-PCR) and sequencing detected the introduced mutations in progeny viruses in all tested leaves. These leaves were also analyzed with a double antibody sandwich enzymelinked immunosorbent assay (DAS-ELISA) for virus concentrations, stored at $-20^{\circ} \mathrm{C}$, and used as inoculum in sap-inoculation experiments.

A lower percentage of potato plants were locally and systemically infected with PVAmB than with PVAmA, PVAmC, and wtPVA at 28 days post-sap inoculation in three independent experiments. In the inoculated leaves, the titers of PVAmB tended to be lower than those of PVAmA and PVAmC (Table 3 ). Titers of all mutant viruses in the systemically infected leaves were five- to 20-fold lower than those of wtPVA (Scheffe's test, $P=0.013$ to 0.071 ) (Table 3). Analysis of progeny viruses with IC-RT-PCR and sequencing revealed no sequence reversions.

PVAmABC was tested on $N$. benthamiana in the aforementioned experiments. No virus accumulation was detected with DAS-ELISA in leaves inoculated by particle bombardment or agroinfiltration in independent experiments. However, two of 17 inoculated plants in three experiments were systemically infected at $21 \mathrm{dpi}$. Systemically infected leaves contained low titers of PVA CP antigen (70 and $260 \mathrm{ng}$ of fresh leaf tissue per gram) as tested with DAS-ELISA and displayed no symptoms. Introduced mutations were detected in the HCpro region with IC-RT-PCR and sequencing. These results showed that PVAmABC was infectious and capable of completing the infection cycle, but its virulence was heavily reduced.

\section{Mutations in HVR alter phenotypic responses to PVA infection in tobacco plants.}

Tobacco plants (cv. Samsun nn) sap-inoculated with wtPVA, PVAmA, PVAmB, or PVAmC displayed no symptoms up to 2 weeks postinoculation, but observation of upper noninoculated leaves under UV light revealed blue fluorescent lesions at 12 to 15 dpi in plants infected by PVAmA, PVAmB, and PVAmC (Fig. 3A). The lesions were also observed following systemic infection of tobacco plants with PVAmC that was engineered to express green fluorescent protein (GFP) (Kelloniemi et al. 2006). A few days after they appeared, the blue fluorescent lesions also became visible under daylight as brown rings with a chlorotic or necrotic center (Fig. 3B). They coincided with the tissue showing GFP fluorescence (Fig. 3C), indicating that they were induced by PVAmC-GFP. Staining for reactive oxygen species (ROS) with nitroblue tetrazolium (NBT) (Fig. 3D) and 3,3'-diaminobenzidine (DAB) (Fig. 3E) indicated that the lesions accumulated superoxide and hydrogen peroxide, respectively.
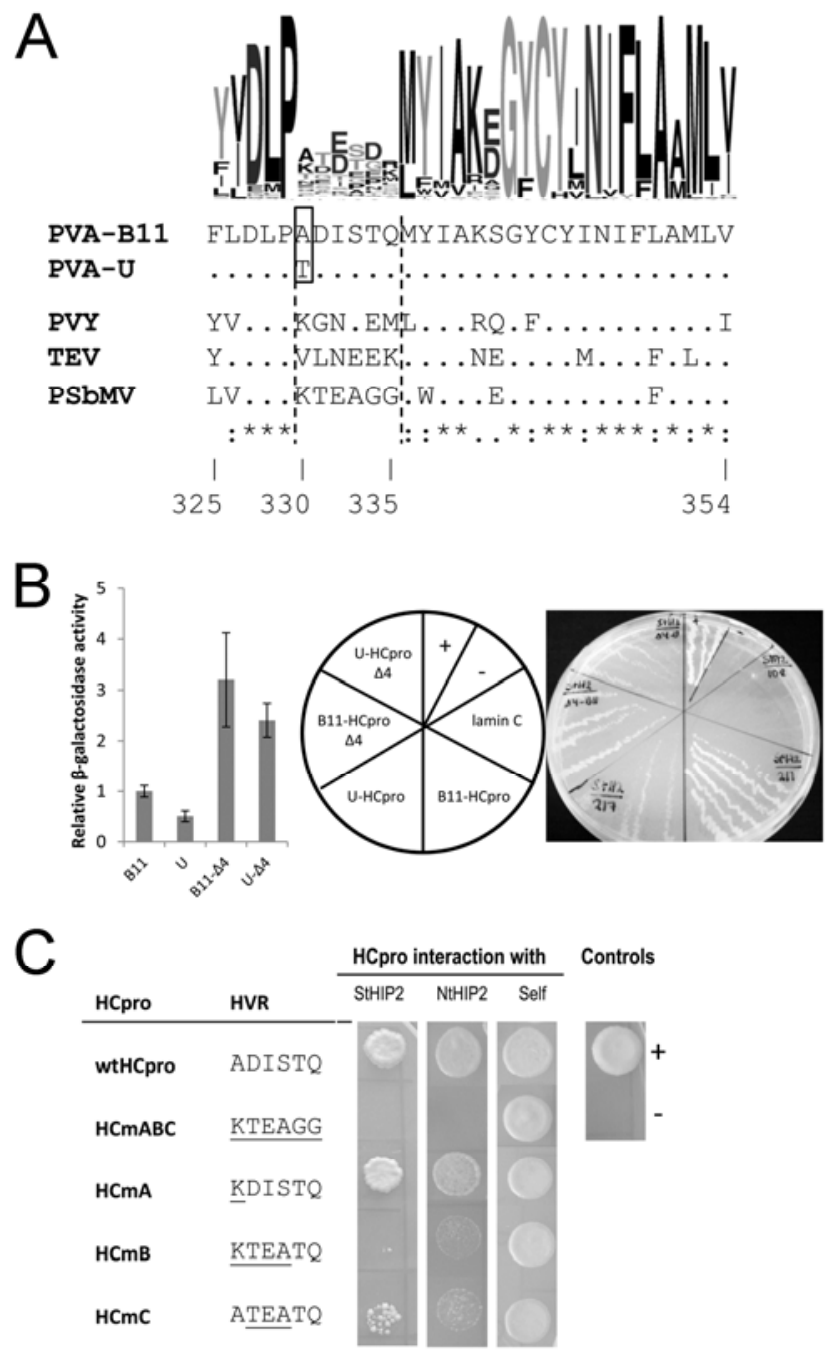

Fig. 2. The highly variable region (HVR) in helper component proteinase (HCpro) influences interactions with HIP2. A, Residues 330 to 335 in Potato virus A (PVA) HCpro define HVR detected by comparison of 47 potyvirus species (bordered by vertical broken lines). B, Interactions of the full-length and C-proximal portions ( $\Delta 4$, residues 230 to 458 ) of the HCpro proteins of PVA strains B11 and U with StHIP2. The C-proximal part differs at residues 330 (Ala in PVA-B11, Thr in PVA-U) and 437 (Ile in PVA-B11, Val in PVA-U). Each bar indicates the mean of relative $\beta$-galactosidase activity $(n=3)$. Error bars indicate standard deviation. Growth of yeast co-transformed to express the interaction partners on selective yeast two-hybrid system (YTHS) medium provided consistent evidence of differences in interactions. The symbols + and - indicate positive and negative YTHS controls, respectively. Human lamin c was included as an additional negative control. Data were acquired 4 days postplating. C, Interactions of wtHCpro of PVA-B11 and HCpro mutants with StHIP2 and NtHIP2. Substituted amino acids are underlined. Growth of co-transformed yeast on selective YTHS medium was observed 5 days (StHIP2) or 7 days (NtHIP2) postplating. 'Self' indicates HCpro self-interaction assessed 4 days postplating. 
Possible involvement of salicylic acid (SA)-mediated signaling in the observed necrotic response was tested in tobacco cv. Xanthi and transgenic Xanthi plants expressing salicylate hydroxylase (NahG) that degrades SA (Friedrich et al. 1995). Symptoms in the NahG transgenic and wt plants of cv. Xanthi (Supplementary Fig. 4) were similar to those observed in cv. Samsun nn following systemic infection with wtPVA, PVAmA, or PVAmC, indicating that SA played no significant role in the observed response.

\section{Mutations in HVR induce expression of defense-related genes in PVA-infected tobacco plants.}

The necrotic symptoms in tobacco leaves systemically infected with PVAmA, PVAmB, and PVAmC were novel to PVA and were associated with mutations in HVR. We further studied these unexpected symptoms by comparing gene expression in the first systemically infected leaves of tobacco plants (cv. Samsun nn) at an early stage of systemic infection with PVAmC. wtPVA and PVAmC were sap-inoculated to the two

Table 1. Comparison of Potato virus A (PVA) mutants and wild-type (wt) PVA for accumulation in agroinoculated leaf tissue of Nicotiana benthamiana and N. tabacum

\begin{tabular}{|c|c|c|c|c|c|c|c|c|}
\hline \multirow[b]{2}{*}{ Virus } & \multicolumn{2}{|c|}{ Mutant $^{\mathrm{a}}$} & \multicolumn{2}{|c|}{ wtPVA } & \multicolumn{4}{|c|}{ Wilcoxon test } \\
\hline & $\mathbf{C} \mathbf{P}^{\mathbf{b}}$ & Quartiles & $\mathbf{C P}^{\mathbf{b}}$ & Quartiles & $n^{c}$ & $\%^{d}$ & $\mathbf{Z}$ & $P$ \\
\hline \multicolumn{9}{|l|}{ N. benthamiana } \\
\hline PVAmA & 16.59 & (11.52 to 28.49 ) & 45.27 & (37.58 to 74.21 ) & 10 & 39 & -2.803 & 0.005 \\
\hline PVAmB & 12.86 & (8.40 to 21.79$)$ & 66.03 & (47.57 to 82.44 ) & 11 & 24 & -2.934 & 0.003 \\
\hline PVAmC & 29.72 & (17.01 to 49.23 ) & 52.64 & (42.67 to 79.72 ) & 11 & 55 & -2.934 & 0.003 \\
\hline PVA-Y63F & 0 & 0 & & n.a. & & & & \\
\hline \multicolumn{9}{|l|}{ N. tabacum } \\
\hline PVAmA & 1.06 & (0.42 to 1.20$)$ & 1.68 & (0.48 to 1.81$)$ & 11 & 69 & -2.934 & 0.003 \\
\hline PVAmB & 0.91 & (0.31 to 1.13$)$ & 1.86 & (0.40 to 2.11$)$ & 13 & 55 & -3.180 & 0.001 \\
\hline PVAmC & 1.15 & (0.88 to 1.31$)$ & 1.31 & (1.08 to 1.50$)$ & 16 & 85 & -3.464 & 0.001 \\
\hline PVA-Y63Fe & 0 & 0 & & n.a. & & & & \\
\hline
\end{tabular}

${ }^{a}$ Viral genomes were introduced into leaves in binary vectors by agroinfiltration. A mutant virus (PVAmA, PVAmB, or PVAmC) and wtPVA were introduced into opposite sides of the leaf midrib. Accumulation (amount of PVA CP antigen) of the mutant was compared with that of wtPVA with the Wilcoxon matched pairs signed-rank test.

${ }^{\mathrm{b}}$ Mean amount of PVA coat protein (CP) antigen (micrograms of fresh leaf tissue per gram) as detected with double-antibody sandwich-enzyme-linked immunosorbent assay using known amounts of purified PVA particles for comparison. n.a., not available.

${ }^{\mathrm{c}}$ The total number of mutant vs. wtPVA pairs compared in two independent experiments.

${ }^{\mathrm{d}}$ Relative amount $(\%)$ of $\mathrm{CP}$ antigen of the mutant compared with wtPVA. Z, test value; $P$, statistical significance.

${ }^{\mathrm{e}}$ A replication-deficient PVA genome achieved by mutation Y63F in the viral genome-linked protein (Germundsson et al. 2007) was included as a negative control.

Table 2. Amounts of Potato virus A (PVA) coat protein (CP) antigen in systemically infected leaves of Nicotiana benthamiana plants inoculated with wildtype PVA (wtPVA) and PVA mutants

\begin{tabular}{|c|c|c|c|c|c|c|c|c|c|c|c|c|}
\hline \multirow[b]{3}{*}{ Virus } & \multicolumn{6}{|c|}{ Experiment 1} & \multicolumn{6}{|c|}{ Experiment 2} \\
\hline & \multicolumn{3}{|c|}{7 dpi } & \multicolumn{3}{|c|}{14 dpi } & \multicolumn{3}{|c|}{8 dpi } & \multicolumn{3}{|c|}{14 dpi } \\
\hline & No. plants ${ }^{\mathrm{a}}$ & $\mathbf{P V A}^{\mathbf{b}}$ & $\%^{c}$ & No. plants & PVA & $\%$ & No. plants & PVA & $\%$ & No. plants & PVA & $\%$ \\
\hline PVAmA & $5 / 6$ & $0.96 \pm 0.92$ & 53 & $6 / 6$ & $26.1 \pm 2.9$ & 82 & $3 / 3$ & $3.66 \pm 1.52$ & 22 & $3 / 3$ & $65.1 \pm 11.1$ & 104 \\
\hline PVAmB & $6 / 6$ & $0.82 \pm 0.41$ & 45 & $6 / 6$ & $19.7 \pm 2.5$ & 62 & $2 / 3$ & $2.51 \pm 0.21$ & 15 & $3 / 3$ & $32.1 \pm 11.4$ & 51 \\
\hline PVAmC & $6 / 6$ & $0.88 \pm 0.45$ & 49 & $6 / 6$ & $25.8 \pm 2.0$ & 81 & $2 / 3$ & $15.29 \pm 3.12$ & 90 & $3 / 3$ & $55.8 \pm 2.9$ & 89 \\
\hline wtPVA & $3 / 3$ & $1.81 \pm 0.08$ & 100 & $3 / 3$ & $31.8 \pm 1.6$ & 100 & $2 / 2$ & $16.96 \pm 3.55$ & 100 & $2 / 2$ & $62.4 \pm 2.7$ & 100 \\
\hline LSD $(S E D)^{d}$ & & $0.88(0.41)$ & & & $3.65(1.72)$ & & & $4.82(2.27)$ & & & $21.2(10.1)$ & \\
\hline
\end{tabular}

${ }^{a}$ The number of systemically infected plants out of the total number of plants inoculated. PVA was detected with double-antibody sandwich-enzyme-linked immunosorbent assay (DAS-ELISA).

${ }^{\mathrm{b}}$ Mean amount of PVA CP antigen (micrograms of fresh leaf tissue per gram \pm standard deviation), as determined with DAS-ELISA using known amounts of purified PVA particles for comparison.

${ }^{\mathrm{c}}$ Relative amounts of CP antigen.

${ }^{\mathrm{d}}$ LSD, least significant difference $(P=0.05)$; SED, standard error of difference.

Table 3. Mean amounts of Potato virus A (PVA) coat protein (CP) antigen in potato inoculated with wild-type (wt) PVA and PVA mutants

\begin{tabular}{|c|c|c|c|c|c|c|}
\hline \multirow[b]{2}{*}{ Virus } & \multicolumn{3}{|c|}{ Inoculated leaves (21 dpi) } & \multicolumn{3}{|c|}{ Systemically infected leaves (28 dpi) } \\
\hline & No. plants ${ }^{\mathrm{a}}$ & $\mathbf{P V A}^{\mathbf{b}}$ & $\%^{\mathrm{c}}$ & No. plants ${ }^{\mathrm{a}}$ & $\mathbf{P V A}^{\mathbf{b}}$ & $\%^{\mathrm{c}}$ \\
\hline PVAmA & $4 / 6$ & $2.92 \pm 0.43$ & 86 & $3 / 6$ & $0.14 \pm 0.01$ & 8 \\
\hline PVAmB & $10 / 23$ & $0.69 \pm 0.30$ & 20 & $3 / 23$ & $0.13 \pm 0.05$ & 8 \\
\hline PVAmC & $19 / 27$ & $2.11 \pm 0.26$ & 62 & $5 / 27$ & $0.53 \pm 0.10$ & 31 \\
\hline wtPVA & $17 / 18$ & $3.40 \pm 0.28$ & 100 & $12 / 18$ & $1.71 \pm 0.25$ & 100 \\
\hline $\operatorname{LSD}(\mathrm{SED})^{\mathrm{d}}$ & & $1.22(0.61)$ & & & $0.30(0.14)$ & \\
\hline
\end{tabular}

${ }^{a}$ The number of PVA-infected plants (detected with double-antibody sandwich-enzyme-linked immunosorbent assay [DAS-ELISA]) out of the total number of plants inoculated in three experiments.

${ }^{b}$ Mean amount of PVA CP antigen (nanograms of fresh leaf tissue per gram \pm standard error) as determined with DAS-ELISA using known amounts of purified PVA particles for comparison

${ }^{c}$ Relative amounts of $\mathrm{CP}$ antigen.

${ }^{\mathrm{d}} \mathrm{LSD}$, least significant difference $(P=0.05)$; SED, standard error of difference. 

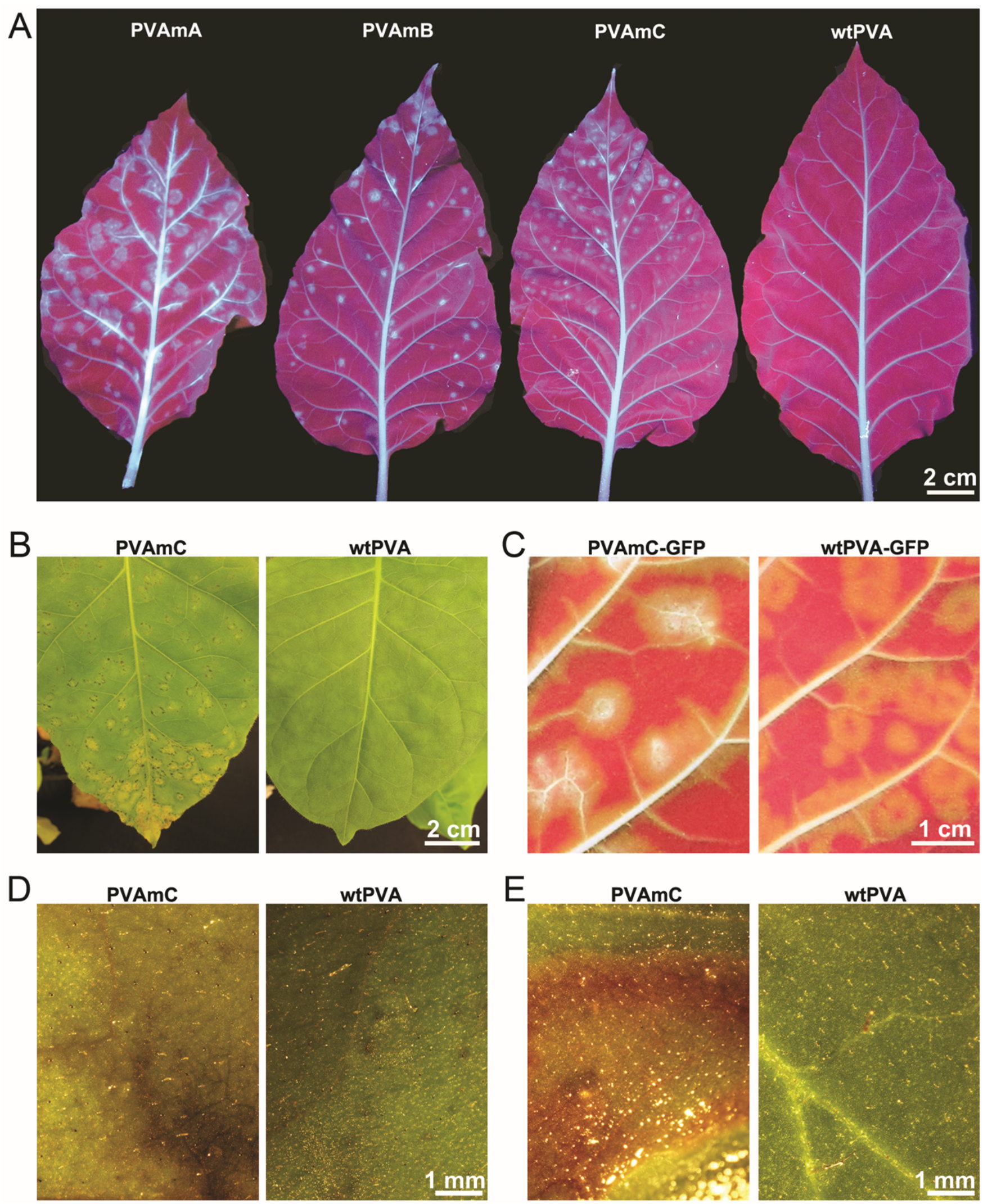

$E$
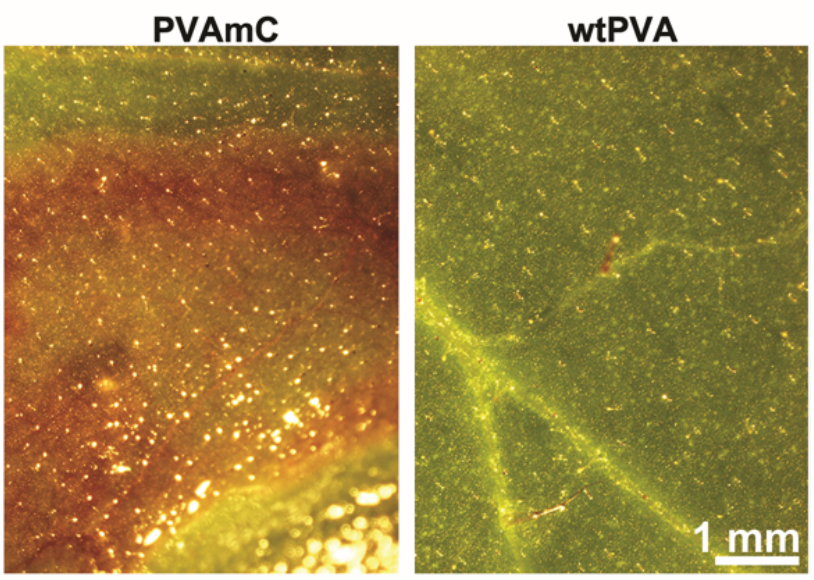

Fig. 3. Phenotypic responses in leaves of Nicotiana benthamiana and tobacco (N. tabacum) systemically infected with Potato virus A-B11 (wtPVA) and the PVA mutants. A, Blue fluorescence observed under UV illumination in tobacco leaves systemically infected with virus mutants 12 days postinoculation. Leaves infected with wtPVA display no fluorescent lesions. B, Necrotic symptoms developed in the leaves infected with PVAmC in contrast to the leaves infected with wtPVA 22 days postinoculation. C, Systemic infection with green fluorescent protein (GFP)-tagged PVAmC (left) reveals that the GFP fluorescence resulting from virus multiplication (seen in orange color owing to strong red autofluorescence of chlorophyll) and the fluorescent lesions indicating a host response (white) are concentric. White fluorescence is absent from the GFP-fluorescent lesions in leaves systemically infected with wtPVAGFP (right). Photos were taken 21 days postinoculation. D, Nitroblue tetrazolium and $\mathbf{E}, 3,3^{\prime}$-diaminobenzidine staining of systemically infected tobacco leaves reveals accumulation of superoxide and hydrogen peroxide, respectively, in the leaves infected with PVAmC. 
lowest, round-shaped leaves of six small tobacco plants or plants were mock-inoculated. The first systemically infected leaf was sampled from each plant at $12 \mathrm{dpi}$, when blue fluorescent lesions (Fig. 3A) were detected under UV light in the leaves of PVAmC-inoculated plants. The experiment was done three times. The sampled leaves were tested with IC-RT-PCR using PVA-specific primers to verify PVA infection.

Gene expression was analyzed using the Agilent tobacco gene expression $4 x 44 \mathrm{k}$ microarray. Comparison of leaves infected with wtPVA and PVAmC revealed approximately 3,000 differentially expressed genes (false discovery rate $<0.05$, adjusted $P$ value $<0.05$, and absolute fold change $\geq 1.6$ ), includ- ing 1,750 upregulated and 1,450 downregulated genes. Changes in expression of genes selected to represent different functional categories are shown in Figure 4. Many genes coding for various types of pathogenesis-related (PR) proteins and genes involved in ethylene (ET)- or jasmonic acid (JA)-mediated signaling pathways were upregulated, whereas only a few marker genes for SA signaling were expressed at a higher level in PVAmC-infected leaves compared with wtPVA leaves. Celldeath marker genes and many secondary metabolism-related genes were induced in PVAmC-infected leaves, whereas genes related to photosynthesis were downregulated. Genes related to defense signaling and secretion varied in their response,
Defense-

\begin{tabular}{|c|c|c|c|c|c|c|}
\hline related function & Protein & Gene & Exp1 & Exp2 & Exp3 & Fold \\
\hline \multirow[t]{6}{*}{ Acidic PR proteins } & PR.1C & SGNU44663! & & & & 19 \\
\hline & PFa & SONUa30510 & & & & 28 \\
\hline & Pro (PR.-O) & SGNUA26sSS & & & & 5.4 \\
\hline & pras & SGN-U422243 & & & & 8.6 \\
\hline & Pratb & SaN-U422245 & & & & 12 \\
\hline & PRS (PRA:) & SGNU430018 & & & & 3.2 \\
\hline \multirow[t]{8}{*}{ Basic PR proteins } & ppe-16 & SGNUALT/4 & & & & 26 \\
\hline & PR2 (GGeso) & Son:U4e6042 & & & & 3.7 \\
\hline & Pros (OAN-B) & SGNU4242557 & & & & 4.1 \\
\hline & PRO (CONA) & SGN-U42485s & & & & 5.5 \\
\hline & Pros (CONN14) & SGNU424560 & & & & 1.6 \\
\hline & PRs (Com 134) & SGN 0424861 & & & & 6.5 \\
\hline & PRA (ctp20) & SGN-U447386 & & & & 7.1 \\
\hline & PRS (cpp1) & SGN-U43001B & & & & 3.2 \\
\hline \multirow{4}{*}{ Neutral PR proteins } & PR:SaA & SGN.U447560 & & & & 7.0 \\
\hline & Pr.508 & SGNUA49698 & & & & 5.3 \\
\hline & PQS (AP24) & SGN 0461533 & & & & 5.1 \\
\hline & 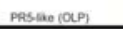 & SGN.U446638 & & & & 9.6 \\
\hline \multirow[t]{2}{*}{ Other PR proteins } & PRE (NSTH) & SGN-U493767 & & & & 4.1 \\
\hline & PPes (1P21) & SGN-Uasont1: & & & & 45 \\
\hline \multirow[t]{8}{*}{ ET response } & ERE 1 & SGN-U430602 & & & & 16 \\
\hline & EPS4 & SQN-UA29417 & & & & 2.1 \\
\hline & ERES & SON-UA72374 & & & & 2.5 \\
\hline & ELP & SQNU461021 & & & & 4.2 \\
\hline & AOxta & SON.U466068 & & & & ns. \\
\hline & ACs2 & SQN-UA29SOS & & & & 2.1 \\
\hline & GPX & SGNUU430528 & & & & 1.8 \\
\hline & Ravi & SON-Ua37915 & & & & 1.6 \\
\hline \multirow[t]{5}{*}{ JA response } & LOX & SGN.U423296 & & & & 17 \\
\hline & Loxtionoliog & SQN-U427745 & & & & 3.5 \\
\hline & LOX.tomalog & SGN.U42746 & & & & 3.8 \\
\hline & Loxthomolos & SGNU427744 & & & & 5.3 \\
\hline & sezi & SGN.U436:C2 & & & & 4.4 \\
\hline \multirow[t]{5}{*}{ SA response } & Satp 2 & Sen-U4te25s2 & & & & ns. \\
\hline & sare $2 a$ & SGNUACAT68 & & & & ns. \\
\hline & sare 20 & SGNUAesss? & & & & 3.6 \\
\hline & $\operatorname{sar} 2 \mathrm{~m}$ & SGN-Uassector & & & & ns. \\
\hline & sipk & SGN.U441835 & & & & ns. \\
\hline \multirow[t]{7}{*}{ ROS } & RBOHB & SGN:U447906 & & & & 1.8 \\
\hline & Nont & SGHUA22495 & & & & ns \\
\hline & GST & SGNU445518 & & & & 2.8 \\
\hline & insoo & sanuaseres & & & & ns \\
\hline & NPX & SGNUALA420 & & & & 2.9 \\
\hline & Aoxe & SGN:UATrese & & & & 2.4 \\
\hline & NDP1 & SGN-UAZZ2ZO4 & & & & 3.4 \\
\hline \multirow[t]{15}{*}{ Defense signaling } & EDstike & SGNU423100 & & & & 2.6 \\
\hline & $\mathrm{PMOA}$ & SGNU42473 & & & & ns \\
\hline & SAG101-140 & SGN.U426447 & & & & ns \\
\hline & wipk & SGNU459178 & & & & 2.0 \\
\hline & NPR1 & SGN-U436436 & & & & ns \\
\hline & Nam-abe pooten 1 & SeN.UA39095 & & & & ns \\
\hline & NTF3 & SGNUA3OSA4 & & & & -1.9 \\
\hline & NTFG & Sow 144577 & & & & ns \\
\hline & $\mathrm{ros}$ Can & SGNUACERer & & & & ns \\
\hline & RUX LRR III (mosece? & SGN-U430206 & & & & -2.9 \\
\hline & RUK DUFzt-axe & SON-U42sT2 & & & & 1.9 \\
\hline & RLX PERCXIake & SON.U459280 & & & & 2.6 \\
\hline & RLK PERX-1ke & SQNutuscoese & & & & -2.1 \\
\hline & RLX LRR XLIake & SGN-U439240 & & & & 2.4 \\
\hline & RUXLRR-XH:be & Sanvusmeso & & & & -6.4 \\
\hline
\end{tabular}

Defense-

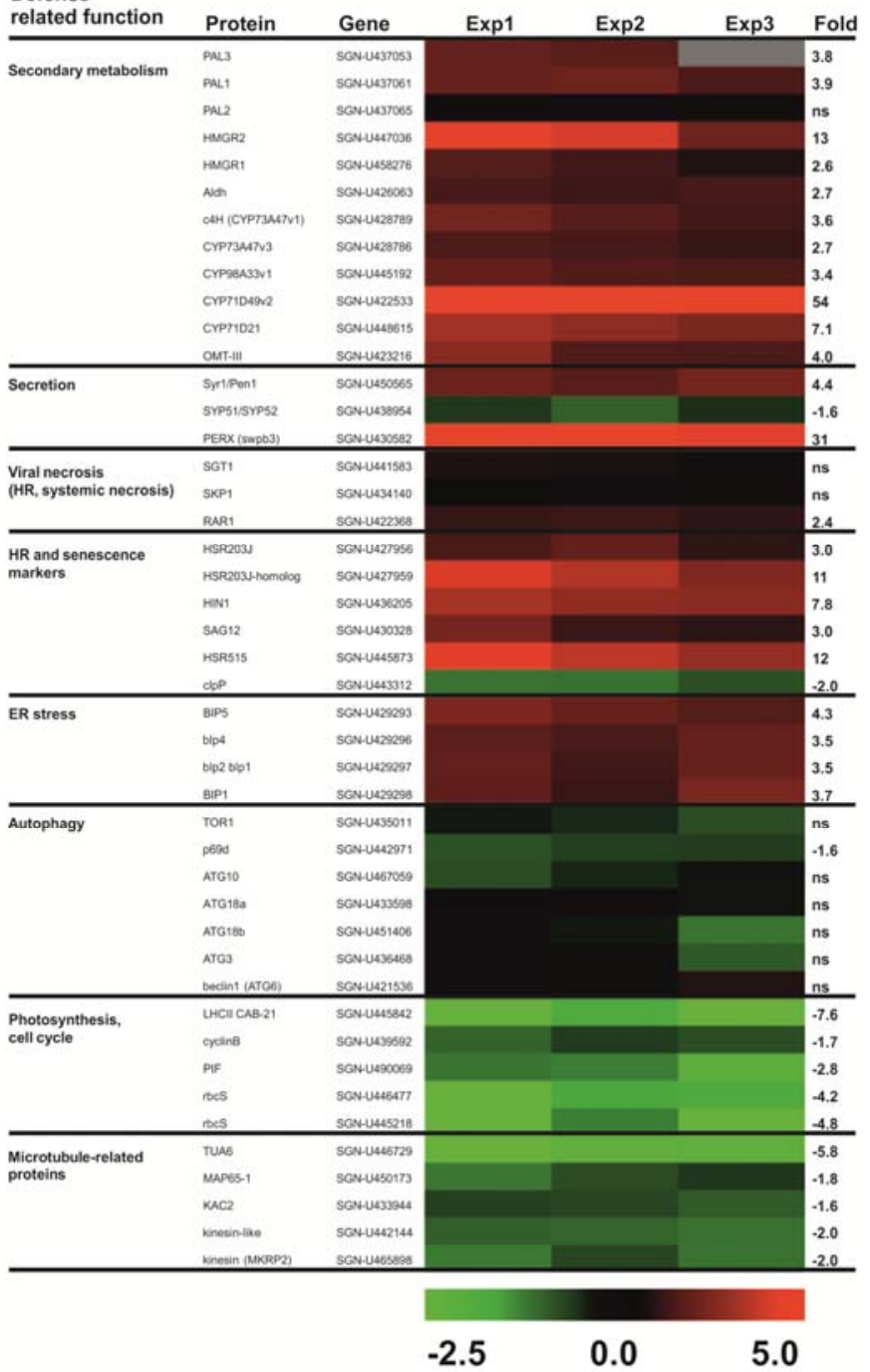

Fig. 4. Microarray analysis to compare gene expression between tobacco leaves systemically infected with wtPVA and PVAmC 12 days postinoculation in three independent experiments (Exp1 to Exp3). The 4x44k Agilent tobacco gene expression microarray was used. The heat map shows results for selected genes belonging to the indicated functional categories. Colors indicate mean relative differences $\left(\log _{2}\right)$ in hybridization signal intensities observed in PVAmC-infected leaves as compared to wtPVA, and the actual fold change values are shown on the right. PR, pathogenesis related; JA, jasmonic acid; ET, ethylene, SA, salicylic acid; HR, hypersensitive response; ROS, reactive oxygen species; ns, statistically not significant (false discovery rate = 0.05 and absolute fold change $\geq 1.6$ ). The gray color indicates that erroneous signals due to scratches were ignored and the results were verified by quantitative real-time reverse transcription-polymerase chain reaction (genes PAL3 and $R L K 902$ ). 
while many MT-associated genes were downregulated. Endoplasmic reticulum (ER) stress-related genes were upregulated, while the expression of autophagy-associated genes was not significantly altered (Fig. 4). Sixteen differentially expressed genes were picked from the different functional categories
(Supplementary Table 1) and were tested for expression in a total of five plants in the three independent experiments with quantitative real-time RT-PCR (qRT-PCR). Results were consistent with those obtained with microarray analysis (Supplementary Fig. 5).
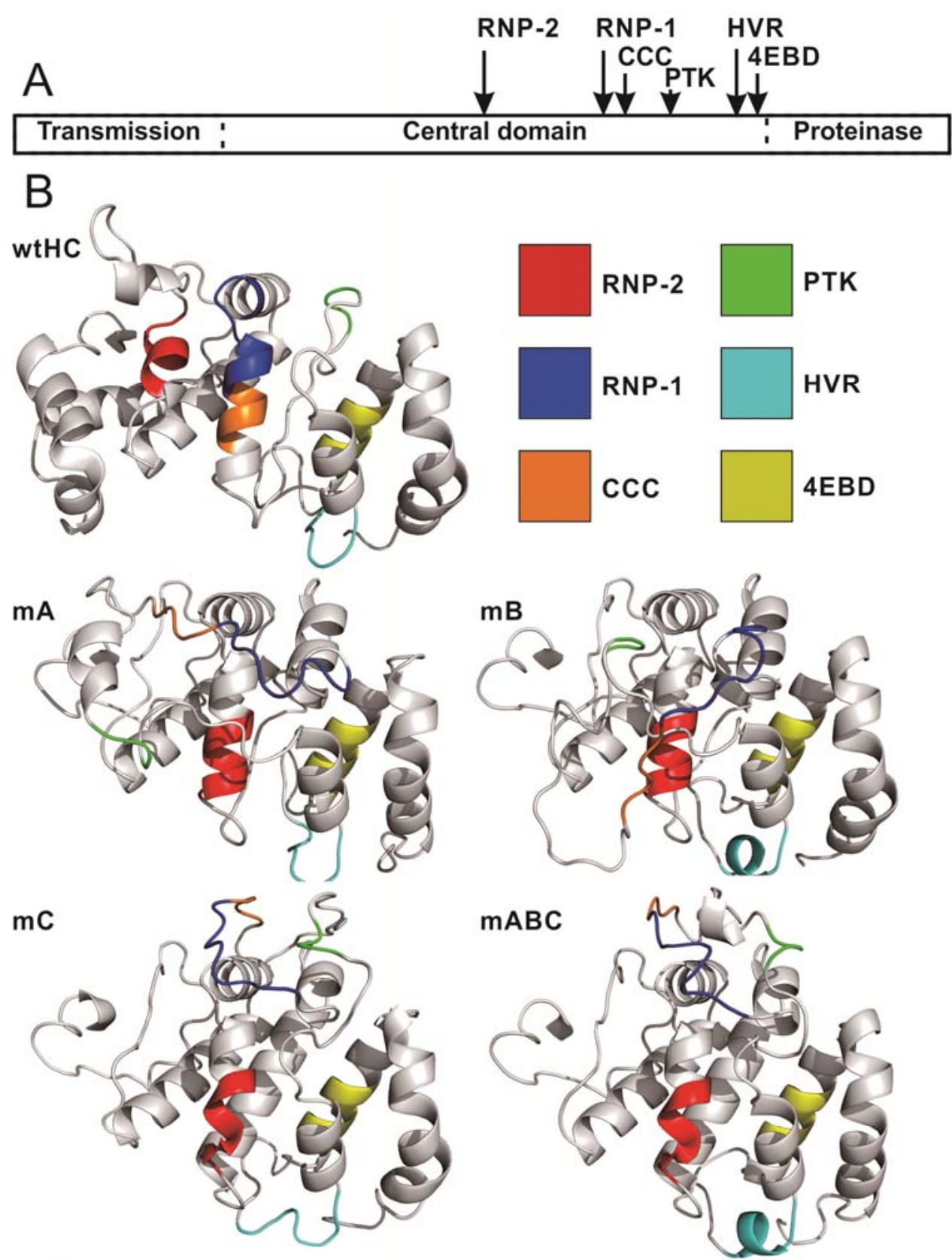

\begin{tabular}{ccccccc}
\cline { 2 - 6 } & $\begin{array}{c}\text { HIP2 } \\
\text { interaction }\end{array}$ & $\begin{array}{c}\text { Virus } \\
\text { titer }\end{array}$ & Necrosis & RNP-1 & CCC & HVR \\
\hline wtHC & +++ & +++ & no & Helix & Helix & Turn \\
$\mathrm{mA}$ & ++ & ++ & yes & Turn & Coil & Turn \\
$\mathrm{mB}$ & + & + & yes & Turn & Coil & Helix \\
$\mathrm{mC}$ & ++ & ++ & yes & Turn & Coil & Turn \\
$\mathrm{mABC}$ & - & - & no & Turn & Coil & Helix \\
\hline
\end{tabular}

Fig. 5. Three-dimensional (3D) structural models of the wild-type helper component proteinase (HCpro) and mutants. A, Locations of the specific amino acid motifs in Potato virus A (PVA) HCpro (458 residues): RNP-2 (residues 248 to 253), RNP-1 (residues 284 to 291), CCC (residues 292 to 294 ), PTK (residues 310 to 312), highly variable region (HVR) (residues 330 to 335), and the eIF4E/eIF(iso)4E-binding motif 4EBD (residues 345 to 351 ). B, The three-dimensional models are based on complete HCpro amino acid sequences, but only the relevant part covering the central region (residues 181 to 380) is shown. The six short regions highlighted with different colors contain conserved amino acid motifs. RNP-1, CCC, and HVR vary in their positions in the predicted models. C, Summary of biological and the predicted conformational differences of wild-type HCpro of PVA-B11 (wtHC) and the four HCpro mutants. 
Microarray hybridization experiments also included samples from mock-inoculated plants. Comparison of gene expression between wtPVA-infected and mock-inoculated plants revealed only a few differentially expressed genes. Hence, the genes detected as differentially expressed in PVAmC-infected plants were largely the same, no matter whether wtPVA-infected or mock-inoculated plants were used for comparison (Supplementary Fig. 6). These results indicated that infection with PVAmC induced considerably larger differences in host gene expression than infection with wtPVA.

\section{Mutations in HVR may cause structural changes in HCpro.}

The structure of HCpro has been difficult to resolve using biochemistry and electron microscopy (Plisson et al. 2003; Ruiz-Ferrer et al. 2005), although the structure of the C-terminal region has been determined in TuMV (Guo et al. 2011). In our present study, structural analysis of the entire PVA HCpro was done using advanced modeling methods with I-TASSER, which is the recommended method for automated protein structure predictions (Roy et al. 2010), using a protein database structure library that includes the structure of the C-terminal region of TuMV (discussed below). The 3D models were aligned using Tm-Align (Zhang and Skolnick 2005). The normalized $\mathrm{Z}$ scores $(>1)$ reflected a good alignment, and the $\mathrm{C}$ score values were higher than $-1.5(-1.25$ to -0.42$)$, indicating a correct fold (Roy et al. 2010).

3D modeling with consideration of intramolecular interactions (Zhang et al. 2011) revealed many $\alpha$-helices and coil structures in the central region of the HCpro of PVA-B11 (wtHC) (Fig. 5B). The models for mutated HCpro proteins were largely similar to wtHC. In all mutants, however, the RNA-binding motif RNP-1 was located in a turn, and the viral movement-associated motif CCC was found in a coil structure; in wtHC, these two motifs were located in a helix structure (Fig. 5). All these predicted changes in HCpro conformation occurred upstream of HVR and did not affect the protein region containing the 4EBD downstream of HVR (Fig. 5). The amino acid substitutions introduced to HVR in mutants PVAmA and PVAmC caused no predictable alteration in the conformation of HVR, whereas the mutations introduced to HVR in PVAmB and PVAmABC changed the modeled structure of HVR (Fig. 5B).

\section{DISCUSSION}

In this study, interactions of PVA HCpro with the MT-associated proteins StHIP2 and NtHIP2 of potato and tobacco were found to be controlled by the hinge domain connecting the $\mathrm{C}$ terminal and central regions of HCpro (Plisson et al. 2003). Most importantly, the hinge region was found to contain a short stretch of six residues (HVR) that are highly variable among potyviruses but apparently sensitive to mutations. Substitutions introduced to the HVR of PVA altered viral virulence. Furthermore, the mutant viruses induced necrosis in systemically infected leaves of tobacco plants, a phenomenon that has not been reported with any strain of PVA or with chimeric clones and recombinants of PVA-B11 or PVA-U (Paalme et al. 2004; Rajamäki et al. 1998; Valkonen et al. 2002). At the level of gene expression, the novel host response to PVA infection in tobacco plants included induction of pathogen defense-related genes and pathways and downregulation of MT-related genes.

The predicted 3D models suggested that mutations within HVR altered protein conformation immediately upstream of HVR in a region containing many conserved functional motifs. Furthermore, predicted structures of PVAmB and PVAmABC showed altered structures within HVR, and these two mutants experienced the largest reduction in fitness in tobacco and potato plants. The correlation between predicted structural changes and the biological responses suggest that HVR acts as an element that regulates the conformation of HCpro and availability of the functional motifs to molecular interactions.

Interaction of PVA HCpro with StHIP2 was originally discovered by screening a potato leaf cDNA library using YTHS and was detected with two in vitro binding assays (Guo et al. 2003). Recently, interactions of NtHIP2 and StHIP2 with HCpro were confirmed in planta with experiments carried out in PVAinfected plant cells using BiFC (Haikonen et al. 2013). In the present study, interactions with StHIP2 and NtHIP2 were also detected for HCpro of PVY and TEV, which infect potato and tobacco plants and whose host range, similar to PVA, is largely limited to species of family Solanaceae (Valkonen et al. 1996). In contrast, HCpro of PSbMV, which infects only a few species of Solanaceae (Aapola et al. 1974), did not interact with StHIP2 and NtHIP2. These results suggested host specificity in HCpro-HIP2 interactions.

Depletion of HIP2 in N. benthamiana by silencing HIP2 to one-fourth of the normal expression level reduces accumulation of PVA in the infected tissues and delays systemic infection (Haikonen et al. 2013). In the present study, two of the four types of mutations introduced to HVR in PVA HCpro altered the structure of HVR, clearly impaired HCpro-HIP2 interactions, and reduced virus accumulation in infected tobacco and potato leaves. Systemic infection and virus accumulation in the systemically infected leaves were also reduced. Taken together, HCpro-HIP2 interactions seem to play an important role in infection of plants with PVA and probably also other potyviruses.

The mutations in HCpro that interfered with HCpro-HIP2 interactions induced an unexpected, novel, necrotic host response in tobacco plants. Previous studies indicate that necrosis and reduction of virus multiplication in systemically infected tobacco leaves are induced through independent pathways, the latter of which is unknown (Komatsu et al. 2010). Analysis of transcriptional responses in tobacco revealed that many PR genes and genes related to phenylpropanoid synthesis or ER stress were induced in leaves infected with PVAmC. A marker gene for HR, HSR203J, and a few other genes characteristic of virus-induced systemic necrosis in tobacco plants (Komatsu et al. 2010; Pontier et al. 1998) were also induced. Genes involved in production of ROS were induced, and ROS accumulation was also detected biochemically in leaf tissues. The fluorescent compound detected under UV illumination in the necrotic tissues may have been scopoletin or scopolin, the production of which is induced by JA (Sharan et al. 1998). Results of previous studies show that signaling via the JA pathway remains unaffected in NahG-expressing tobacco plants (Mur et al. 2006) and, indeed, the necrotic response was also detected in tobacco plants expressing NahG. More importantly, the results on NahG plants indicated that the SA-mediated pathway was not involved in the necrotic response. Taken together, our results implicating an HR-like response induced in tobacco by mutations in the HVR of PVA are in agreement with previous studies showing that HR is not dependent on SA but relies on JA-mediated signaling (Kiba et al. 2003).

Genes related to secondary metabolism were upregulated in PVAmC-infected plants as compared with wtPVA-infected plants, whereas genes involved in photosynthesis or energy metabolism were downregulated, consistent with jasmonates as positive regulators of defense-related secondary metabolism and negative regulators of photosynthesis genes including chlorophyll a/b-binding proteins and ribulose-1,5-bisphosphate carboxylase oxygenase (Reinbothe et al. 1994). The expression pattern of PR genes and lack of induction of NPRl sug- 
gested that the response was not that of NPR1-dependent systemic acquired resistance or induced systemic resistance (Van Loon and Van Strien 1999). The necrotic response was probably not associated with autophagy (Bilgin et al. 2003) because no induction of autophagy-related genes was observed. The response included little evidence for the unfolded protein response (Ye et al. 2011); on the contrary, many ER stress-related genes were upregulated (Leborgne-Castel et al. 1999). Taken together, plant response to infection with PVAmC shared many features of $\mathrm{HR}$, suggesting a hypothesis according to which the predicted structural changes in HCpro 'revealed' the virus-associated molecular patterns to the host innate immunity system and induced a defense response combining cell death and inhibition of virus accumulation (Jones and Dangl 2006). Subsequently, the suboptimal interaction of HCpro with HIP2 might release HIP2 to mediate signaling that resulted in necrotic response in the systemically infected parts of plants.

Many MT-associated genes were downregulated in PVAmCinfected leaves, including the $\alpha$-tubulin gene TUA6 (Gillespie et al. 2002) and the gene for MT cross-linking protein MAP65-1 (Tulin et al. 2012), suggesting that an unbalanced HCpro-HIP2 interaction may disrupt MT network-related functions. Interactions of SPR2, the HIP2 homolog in Arabidopsis, with receptor-like kinases (RLK) and transcription factors (Mukhtar et al. 2011) suggest a link from HIP2 to MT and immune responses. Many RLK are upregulated in pathogen defense, and approximately 50\% of RLK in Arabidopsis are upregulated by at least two different stress inducers (Afzal et al. 2008; Lehti-Shiu et al. 2009). In our study, the $R L K$ genes showed particularly contrasting changes in their expression, with some upregulated and others downregulated upon infection with PVAmC. The RLK class $L R R-X I$ genes may be upregulated or downregulated as a response to biotic stress (Lehti-Shiu et al. 2009), and this was observed with the homologous tobacco genes tested in our study. These results are compatible with the role of MT in plant defense signal amplification (Qiao et al. 2010; Shi et al. 2009; Yao et al. 2011), which may involve HIP2 in integration of defense signaling networks and suggests that HCpro may interact with HIP2 to interfere with host signaling for antiviral defense.

Mutated viruses with reduced or lost MT interactions may be the best suited tools for studying the roles of MT in virus infection (Harries and Ding 2011). Our present study identified a new regulatory element in HCpro that affects potyvirushost interactions via the MT-associated protein HIP2. Previous studies indicate that Tobacco mosaic virus and Potato mop-top virus (family Virgaviridae) can regulate MT dynamics and organization, and virus-MT interactions influence virus movement or accumulation (Ashby et al. 2006; Ouko et al. 2010; Ruggenthaler et al. 2009; Wright et al. 2010). Our study shows that PVA, a member of the Potyviridae family, may also regulate host functions via the MT network.

\section{MATERIALS AND METHODS}

\section{Structural modeling.}

Secondary structures were predicted for HCpro of PVA-B11 (GenBank accession number AJ296311), PVA-U (AJ131402), PVY-Nevski (FR837956), TEV-HCH10 (DQ986288), and PSbMV-NY (X89997). Predictions were made using the NPS@ server (Combet et al. 2000) and Jnet (v2.2) (Cole et al. 2008). Putative coiled-coil regions were analyzed with COILS (Lupas et al. 1991).

For 3D modeling, structural analysis was done using ITASSER (Roy et al. 2010). I-TASSER combines threading, $a b$ initio modeling, and atomic-level structure refinement approaches and is based on the secondary structure-enhanced profile-profile threading alignment and iterative threading assembly refinement. A scoring function (C score) estimates the accuracy of the I-TASSER prediction (Roy et al. 2010; Zhang 2008). In brief, the submitted sequences and the predicted secondary structures were analyzed with a protein database structure library (including the structure of the C-terminal part of TuMV HCpro; Guo et al. 2011), via the LOMETS meta-threading server to identify the best possible templates. They were split into fragments based on the sequence template alignments and were reassembled into a full-length model. The models were refined by a hydrogen-bonding network (REMO) and atomic-level protein structure (FG-MD) analyses. The HCpro sequences of PVA-B11, PVAmA, PVAmB, PVAmC, and PVAmABC were subjected to 3D analysis. The 3D models were aligned using Tm-Align (Zhang and Skolnick 2005).

\section{YTHS.}

The cDNA clones of StHIP2 (GenBank accession number HE653966) and NtHIP2 (HE649915) and their cloning to YTHS vectors (Haikonen et al. 2013), as well as preparation of seven YTHS constructs used for expression of PVA-B11 HCpro and truncated forms of HCpro (Ala-Poikela et al. 2011) have been described previously. The constructs for expression of HCpro of PVA-U (Paalme et al. 2004), five new truncated forms of PVA-B11 HCpro $(\Delta 2, \Delta 3, \Delta 10, \Delta 12$, and $\Delta 14)$, and the mutated HCpro proteins $\mathrm{mABC}, \mathrm{mA}, \mathrm{mB}$, and $\mathrm{mC}$ were prepared in this study as described (Ala-Poikela et al. 2011), using primers containing Bam HI and SalI restriction sites for cloning. PCR fragments were cloned into the YTHS vectors pGBKT7 and pGADT7 for fusion with the DNA-binding domain or transcription activation domain, respectively (Clontech, Mountain View, CA, U.S.A.). The reading frame and orientation of inserts were verified with restriction analysis and sequencing. Sequencing was carried out with an Applied Biosystems dye terminator (v3.1) kit and a 3100 capillary sequence analyzer at the sequencing core facility of the Haartman Institute, University of Helsinki.

Yeast (strains AH109 or Y187; Clontech) were cotransformed with plasmids coding for activation domain and binding domain fusion proteins using the lithium acetate transformation protocol (Clontech). Synthetic minimal medium lacking leucine and tryptophan was used to select for transformed yeast. Proteinprotein interactions were detected by growth of AH109 on medium lacking adenine, histidine, leucine, and tryptophan at $30^{\circ} \mathrm{C}$. Growth was observed for up to 14 days. For comparisons of relative interaction strengths, induction of the LacZ reporter gene was assessed in the yeast strain Y187 (Clontech) by measuring $\beta$-galactosidase activity from pelleted and lysed cells using 5-bromo-4-chloro-3-indolyl- $\beta$-D-galactopyranoside (X-gal) as a substrate (Ala-Poikela et al. 2011; Möckli and Auerbach 2004). The interaction between StHIP2 and B11HCpro was set to $100 \% \beta$-galactosidase activity to determine the relative strength of interactions in other samples. A vector pair (pGADT7-T and pGBKT7-53) supplied by Clontech was used as a positive control.

\section{BiFC.}

The HCpro-encoding sequences of PVA-B11, TEV-HCH10, and PVY-Nevski were cloned into the BiFC vectors (Zamyatnin et al. 2006) in a previous study (Ala-Poikela et al. 2011). The HCpro-encoding sequence of PSbMV-NY (Guo et al. 2001) was cloned as described (Ala-Poikela et al. 2011) into the NcoI site in the plasmids pRT-YN and pRT-YC, so that the $\mathrm{N}$ - and C-proximal halves of the yellow fluorescent protein (YN and YC, respectively) could be expressed in fusion with the N-terminus of HCpro. Of note, according to our experience, fusion of $\mathrm{YC}$ or $\mathrm{YN}$ to the $\mathrm{N}$-terminus of PVA HCpro does not inter- 
fere with interactions and functions of HCpro in planta, whereas C-terminal YC or YN fusions may compromise self-interaction of HCpro and its silencing suppression activities. Similar results have been reported in other studies and potyviruses (Zilian and Maiss 2011). The expression cassettes were further subcloned into the binary vector pLH700 using HindIII. NtHIP2 and StHIP2 were amplified as for YTHS but using primers with SalI sites. They were ligated to XhoI-digested binary vectors pLH-YN or pLH-YC (Zamyatnin et al. 2006) to be expressed with YN or YC fused to the C-terminus.

\section{Western blot analysis.}

Total protein was extracted from liquid cultures of transformed yeast (strain AH109) using a modified trichloroacetic acid precipitation method (Ala-Poikela et al. 2011; Volland et al. 1994). Monoclonal antibodies to the activation and binding domains (dilution 1:12,000; Clontech) and horseradish peroxidase (HRP)-conjugated sheep anti-mouse antibodies (1:120,000; GE Healthcare, Buckinghamshire, U.K.) were used to detect the proteins. The HRP conjugate was detected with an enhanced chemiluminescence substrate (Super Signal West Femto, Thermo Scientific, Rockford, IL, U.S.A.).

\section{Plant material.}

Nicotiana tabacum cv. Samsun nn and N. benthamiana plants were grown from seeds. PVA-susceptible progeny line v2-134 (Hämäläinen et al. 2000) originating from a diploid potato cross (Valkonen et al. 1994; Watanabe et al. 1994) was propagated as described (Vuorinen et al. 2010). Plants were grown in growth rooms (photoperiod $16 \mathrm{~h}$, light intensity 200 $\mu \mathrm{E} \mathrm{m} \mathrm{m}^{-2} \mathrm{~s}^{-1}$, temperature 22 to $24^{\circ} \mathrm{C}$ [light] and 18 to $20^{\circ} \mathrm{C}$ [dark], relative humidity $40 \%)$ with fertilizer (N/P/K, 16:9:22 [Yara, Espoo, Finland]) mixed in water (0.3 g/liter) that was given in every watering.

\section{Mutation of HCpro and construction of virus mutants.}

The $5^{\prime}$ end of the PVA genome consisting of the $5^{\prime}$ untranslated region, $\mathrm{P} 1$, HCpro, and $\mathrm{P} 3$ regions was amplified by $\mathrm{PCR}$ from the infectious cDNA clone of PVA-B11 and was cloned into pGEM-T (Promega, Madison, WI, U.S.A.). For mutagenesis, the entire plasmid was amplified using Phusion, and the reverse and forward primers were used to introduce the desired nucleotide and amino acid substitutions. The primers or the blunt-end PCR products were phosphorylated with T4 polynucleotide kinase (New England Biolabs, Ipswich, MA, U.S.A.), followed by self-ligation of the PCR products. The constructs were verified with restriction digestion and sequencing. The mutated HCpro coding sequences were cloned into the infectious clone of PVA expressing GFP from the NIb/CP junction (Kelloniemi et al. 2006) or lacking GFP (Paalme et al. 2004; Puurand et al. 1996), using the SexAI and NruI sites. The obtained PVA clones were verified with restriction analysis and sequencing of the mutated sites.

\section{Virus inoculation.}

Viral clones were inoculated biolistically to two leaves per plant using a Helios Gene Gun (Bio-Rad Laboratories, Hercules, CA, U.S.A.) or HandyGun (Ala-Poikela et al. 2011; Sikorskaite et al. 2010). Sap-inoculation was done as described (Rajamäki et al. 1998) using systemically infected leaves of N. benthamiana to prepare the inoculum. Virus concentration in the leaves was estimated with DAS-ELISA and was equalized between inocula of different virus mutants and wtPVA by diluting the sap with sap extracted from healthy leaves.

For agroinoculation, infectious PVA clones were transferred to the binary vector pCAMBIA0390 (Cambia, Brisbane, Australia) using KpnI and SalI sites and were transformed into $\mathrm{Ag}$ - robacterium tumefaciens C58C1 (pGV2260). Agrobacterium cultures $\left(\mathrm{OD}_{600}=0.3\right.$ or 0.6$)$ were infiltrated into restricted areas (spots) on the leaves of $N$. benthamiana or $N$. tabacum. For comparison of virus accumulation in the inoculated leaves, two different viruses were inoculated onto opposite sides of the leaf midrib.

\section{Histochemical staining.}

Histochemical staining for superoxide and hydrogen peroxide with NBT and DAB, respectively, was conducted as described (Schraudner et al. 2001) with some modifications. Discs from systemically infected leaves were excised with a cork borer and were immersed in the staining solution $(0.1 \%$ [wt/vol] DAB, $10 \mathrm{mM}$ 2-( $\mathrm{N}$-morpholino)ethanesulfonic acid [pH 6.5], or $0.1 \%$ [wt/vol] NBT, $10 \mathrm{mM}$ sodium azide, $50 \mathrm{mM}$ potassium phosphate [ $\mathrm{pH} 7.5])$ and were vacuum infiltrated for $30 \mathrm{~min}$. Discs were floated on the staining solution in darkness overnight, were rinsed with water to remove excess dye, and were observed under stereomicroscope.

\section{Virus detection.}

PVA was detected with DAS-ELISA using a monoclonal PVA-CP-specific antibody (MAb 58/0) and the alkaline phosphatase-conjugated MAb 58/0, both obtained from SASA (Edinburgh, U.K.) as described (Ala-Poikela et al. 2011). Leaf samples were weighed and ground in ELISA sample buffer at 1 $\mathrm{g}$ to $10 \mathrm{ml}$ (tobacco) or $1 \mathrm{~g}$ to $3 \mathrm{ml}$ (potato), and aliquots of 100 $\mu \mathrm{l}$ were transferred to a microtiter plate coated with PVA antibodies. Known amounts of purified PVA virions were included for comparison to estimate virus concentration. Virus concentrations were log-transformed, and differences were tested with analysis of variance. Pair-wise comparisons were made with Scheffe's test, using the statistical package PASW (v.18.0.3).

Virions of PVA were immunocaptured with MAb 58/0 from the same leaf samples that were used for DAS-ELISA. cDNA was synthesized with Moloney murine leukemia virus (MMLV) reverse transcriptase (Promega) using random hexamer primers. The mutated region of the HCpro-encoding sequence was amplified with PCR using a high-fidelity DNA polymerase (Dynazyme II; Finnzymes, Espoo, Finland) and PVA-specific primers. PCR products were sequenced directly without cloning to confirm that mutations were retained.

In the agroinoculated leaves, the concentration of the PVA CP antigen was determined with DAS-ELISA at 3.5 dpi in leaf tissue excised with a cork borer from the middle of the agroinfiltrated area. Virus concentrations of the viral mutant and wtPVA (or the noninfectious mutant PVA-Y63F) inoculated to the opposite sides of the midrib of the same leaf were compared pair-wise, using the Wilcoxon matched pairs signed-rank test.

\section{Microarray analysis.}

RNA was extracted using homemade Trizol (Caldo et al. 2004). Equal amounts of RNA from each of the six plants infected with the same virus (PVAmC or wtPVA) in the experiment were pooled and were further purified using an RNeasy plant mini kit (Qiagen, Hilden, Germany). Oligo(dT)-primers were used for first- and second-strand cDNA synthesis. Subsequently, cDNA was transcribed to antisense RNA using an Amino Allyl MessageAmp kit (Life Technologies, Carlsbad, CA, U.S.A.) to incorporate amino allyl-dUTP. The quality of the resulting RNA was tested with a Bioanalyzer (Agilent, Santa Clara, CA, U.S.A.) and was labeled with $\mathrm{Cy} 3$ or $\mathrm{Cy} 5$ (GE Healthcare, Little Chalfont, U.K.). Hybridization to the tobacco 4x44K 60mer oligo array (design ID 021113; Agilent) was done according to the manufacturer's instructions. Arrays were scanned using a GenePix 4200 AL microarray scanner (Molecular Devices, Sunnyvale, CA, U.S.A.). Image analysis 
was done using GenePixPro 6.1 software (Molecular Devices). Fluorescence intensities were normalized using the quantile normalization function. Differences in log intensities were tested with the moderated $t$ test, and the resulting $P$ values were transferred to false discovery rate values using the limma R/Bioconductor package (Smyth 2004).

Probe sequences were compared with the Tobacco Unigene database sequences (SOL Genomics network) using BLAST+ command-line applications (National Center for Biotechnology Information $[\mathrm{NCBI}]$ ), and the target genes were annotated. For an overview of the overrepresented gene ontology (GO) classes and pathways (Kyoto Encyclopedia of Genes and Genomes), GO annotations to the closest homologs in Arabidopsis were used for a GO enrichment test on differentially expressed genes. Results were viewed with ClueGo (Bindea et al. 2009) or BinGO (Maere et al. 2005), which are plug-ins for the Cytoscape network visualization tool (Cline et al. 2007). Another tool we used to view the pathways was MapMan (Thimm et al. 2004). Probes were also associated with selected sets of marker genes from pathways of interest. The HEAT map was drawn using normalized log intensities using MultiExperiment Viewer (MeV v4.81) (Saeed et al. 2006). The MIAME (minimum information about a microarray experiment) guidelines for data deposition were followed (Edgar and Barrett 2006). The raw data, results of the statistical analysis and the annotations are available at NCBI Gene Expression Omnibus database under accession number GSE42833.

\section{qRT-PCR.}

Total RNA $(3 \mu \mathrm{g})$ was DNase treated and first-strand cDNA was synthesized, using M-MLV reverse transcriptase (Promega) and random primers. Resulting cDNA (50 $\mu \mathrm{l})$ was diluted fivefold to a final volume of $250 \mu \mathrm{l}$. qPCR was carried out using the Light Cycler 480 Real Time PCR detection system (Roche, Mannheim, Germany). Primers were designed for 16 genes representing different functional classes (Fig. 4) and the gene for glyceraldehyde-3-phosphate dehydrogenase GapC (GenBank accession number AJ133422, N. tabacum unigene SGN-U515093) that was used as an internal control for data normalization. The primers were tested for specificity by sequencing the PCR products. The PCR master mix $(15 \mu \mathrm{l})$ contained $4 \mu \mathrm{l}$ of cDNA, $7.5 \mu \mathrm{l}$ of LightCycler 480 SYBR Green I master mix $(2 \times), 0.75 \mu \mathrm{l}(5 \mu \mathrm{M})$ of each primer, and $2 \mu \mathrm{l}$ of water. The PCR program was denaturation $\left(95^{\circ} \mathrm{C}\right.$ for $\left.10 \mathrm{~min}\right)$ followed by 45 cycles of amplification $\left(95^{\circ} \mathrm{C}\right.$ for $10 \mathrm{~s}, 60^{\circ} \mathrm{C}$ for $10 \mathrm{~s}$, and $72^{\circ} \mathrm{C}$ for $10 \mathrm{~s}$ ). Primer efficiencies were calculated based on the standard curves of a dilution series of cDNA using the LightCycler 480 program. The efficiency values were used to calculate the fold differences between samples. The relative expression ratios of genes were calculated as described (Pfaffl 2001).

\section{ACKNOWLEDGMENTS}

We thank D. Guo (Wuhan University, China) for helpful discussions at the beginning of the project, P. Somervuo (Institute of Biotechnology, University of Helsinki) for scanning the microarrays and statistical analysis of the data, previous members of our laboratory, E. Goytia and A. Vuorinen, for help in making various plasmid constructs, and S. Siddiqui (our laboratory) for a few primers. This study was financially supported by the Academy of Finland (grants 1118766,1134759 , and 1253126 to J. P. T. Valkonen) and The Finnish Doctoral Program in Plant Sciences (to T. Haikonen).

\section{LITERATURE CITED}

Aapola, A. A., Knesek, J. E., and Mink, G. I. 1974. The influence of inoculation procedure on the host range of Pea seed-borne mosaic virus. Phytopathology 64:1003-1006.
Afzal, A. J., Wood, A. J., and Lightfoot, D. A. 2008. Plant receptor-like serine threonine kinases: Roles in signaling and plant defense. Mol. Plant-Microbe Interact. 21:507-517.

Ala-Poikela, M., Goytia, E., Haikonen, T., Rajamäki, M.-L., and Valkonen, J. P. T. 2011. Helper Component Proteinase of the genus Potyvirus is an interaction partner of translation initiation factors eIF(iso)4E and eIF4E and contains a 4E binding motif. J. Virol. 85:6784-6794.

Andrejeva, J., Puurand, Ü., Merits, A., Rabenstein, F., Järvekülg, L., and Valkonen, J. P. T. 1999. Potyvirus helper component-proteinase and coat protein $(\mathrm{CP})$ have coordinated functions in virus-host interactions and the same CP motif affects virus transmission and accumulation. J. Gen. Virol. 80:1133-1139.

Ashby, J., Boutant, E., Seemanpillai, M., Sambade, A., Ritzenthaler, C. and Heinlein, M. 2006. Tobacco mosaic virus movement protein functions as a structural microtubule-associated protein. J. Virol. 80:83298344

Bilgin, D. D., Liu, Y., Schiff, M., and Dinesh-Kumar, S. P. 2003. P58IPK, a plant ortholog of double-stranded RNA-dependent protein kinase PKR inhibitor, functions in viral pathogenesis. Dev. Cell 4:651-661.

Bindea, G., Mlecnik, B., Hackl, H., Charoentong, P., Tosolini, M., Kirilovsky, A., Fridman, W.-H., Pagès, F., Trajanoski, Z., and Galon, J. 2009. ClueGO: A Cytoscape plug-in to decipher functionally grouped Gene Ontology and pathway annotation networks. Bioinformatics 25:1091-1093.

Buschmann, H., Fabri, C. O., Hauptmann, M., Hutzler, P., Laux, T., Lloyd, C. W., and Schäffner, A. R. 2004. Helical growth of the Arabidopsis mutant tortifolial reveals a plant-specific microtubule-associated protein. Curr. Biol. 14:1515-1521.

Caldo, R. A, Nettleton, D., and Wise, R. P. 2004. Interaction-dependent gene expression in $M l a$-specified response to barley powdery mildew. Plant Cell 16:2514-2528.

Carrington, J. C., Cary, S. M., Parks, T. D., and Dougherty, W. G. 1989. A second proteinase encoded by a plant Potyvirus genome. EMBO J. 8:365-370.

Cline, M. S., Smoot, M., Cerami, E., Kuchinsky, A., Landys, N., Workman, C., Christmas, R., Avila-Campilo, I., Creech, M., Gross, B., Hanspers, K., Isserlin, R., Kelley, R., Killcoyne, S., Lotia, S., Maere, S., Morris, J., Ono, K., Pavlovic, V., Pico, A. R., Vailaya, A., Wang, P.-L., Adler, A., Conklin, B. R., Hood, L., Kuiper, M., Sander, C., Schmulevich, I., Schwikowski, B., Warner, G. J., Ideker, T., and Bader, G. D. 2007. Integration of biological networks and gene expression data using Cytoscape. Nat. Protoc. 2:2366-2382.

Cole, C., Barber, J. D., and Barton, G. J. 2008. The Jpred 3 secondary structure prediction server. Nucleic Acids Res. 36:W197-W201.

Combet, C., Blanchet, C., Geourjon, C., and Deléage, G. 2000. NPS@: Network protein sequence analysis. Trends Biochem. Sci. 25:147-150.

Cronin, S., Verchot, J., Haldeman-Cahill, R., Schaad, M. C., and Carrington, J. C. 1995. Long-distance movement factor: A transport function of the Potyvirus helper component proteinase. Plant Cell 7:549-559.

Dolja, V. V., Herndon, K. L., Pirone, T. P., and Carrington, J. C. 1993. Spontaneous mutagenesis of a plant potyvirus genome after insertion of a foreign gene. J. Virol. 67:5968-5975.

Edgar, R., and Barrett, T. 2006. NCBI GEO standards and services for microarray data. Nat. Biotechnol. 24:1471-1472.

Friedrich, L., Vernooij, B., Gaffney, T., Morse, A., and Ryals, J. 1995. Characterization of tobacco plants expressing a bacterial salicylate hydroxylase gene. Plant Mol. Biol. 29:959-968.

Germundsson, A., Savenkov, E. I., Ala-Poikela, M., and Valkonen, J. P. T 2007. VPg of Potato virus A alone does not suppress RNA silencing but affects virulence of a heterologous virus. Virus Genes 34:387-399.

Gillespie, T., Boevink, P., Haupt, S., Roberts, A. G., Toth, R., Valentine, T. Chapman, S., and Oparka, K. J. 2002. Functional analysis of a DNAshuffled movement protein reveals that microtubules are dispensable for the cell-to-cell movement of Tobacco mosaic virus. Plant Cell 14:12071222.

Guo, B., Lin, J., and Ye, K. 2011. Structure of the autocatalytic cysteine protease domain of Potyvirus helper-component proteinase. J. Biol. Chem. 286:21937-21943.

Guo, D., Merits, A., and Saarma, M. 1999. Self-association and mapping of interaction domains of helper component-proteinase of potato A potyvirus. J. Gen. Virol. 80:1127-1131.

Guo, D., Spetz, C., Saarma, M., and Valkonen, J. P. T. 2003. Two potato proteins, including a novel RING finger protein (HIP1), interact with the potyviral multifunctional protein HCpro. Mol. Plant-Microbe Interact. 16:405-410.

Haikonen, T., Rajamäki, M.-L., and Valkonen, J. P. T. 2013. Interaction of the microtubule-associated host protein HIP2 with viral helper component proteinase is important in infection with Potato virus A. Mol. Plant-Microbe Interact. 26:734-744.

Harries, P., and Ding, B. 2011. Cellular factors in plant virus movement: 
At the leading edge of macromolecular trafficking in plants. Virology 411:237-243.

Hämäläinen, J. H., Kekarainen, T., Gebhardt, C., Watanabe, K. N., and Valkonen, J. P. T. 2000. Recessive and dominant genes interfere with the vascular transport of Potato virus $A$ in diploid potatoes. Mol. PlantMicrobe Interact. 13:402-412.

Jones, J. D. G., and Dangl, J. L. 2006. The plant immune system. Nature 444:323-329.

Kasschau, K. D, and Carrington, J. C. 2001. Long-distance movement and replication maintenance functions correlate with silencing suppression activity of potyviral HC-Pro. Virology 285:71-81.

Kasschau, K. D, Cronin, S., and Carrington, J. C. 1997. Genome amplification and long-distance movement functions associated with the central domain of tobacco etch potyvirus helper component-proteinase. Virology 228:251-262.

Kelloniemi, J., Mäkinen, K., and Valkonen, J. P. T. 2006. A potyvirusbased gene vector allows producing active human S-COMT and animal GFP, but not human sorcin, in vector-infected plants. Biochimie 88:505-513

Kiba, A., Tomiyama, H., Takahashi, H., Hamada, H., Ohnishi, K., Okuno, T., and Hikichi, Y. 2003. Induction of resistance and expression of defense-related genes in tobacco leaves infiltrated with Ralstonia solanacearum. Plant Cell Physiol. 44:287-295.

Komatsu, K., Hashimoto, M., Ozeki, J., Yamaji, Y., Maejima, K., Senshu, H., Himeno, M., Okano, Y., Kagiwada, S., and Namba, S. 2010. Viralinduced systemic necrosis in plants involves both programmed cell death and the inhibition of viral multiplication, which are regulated by independent pathways. Mol. Plant-Microbe Interact. 23:283-293.

Leborgne-Castel, N., Jelitto-Van Dooren, E. P. W. M., Crofts, A. J., and Denecke, J. 1999. Overexpression of BiP in tobacco alleviates endoplasmic reticulum stress. Plant Cell 11:459-469.

Lehti-Shiu, M. D., Zou, C., Hanada, K., and Shiu, S.-H. 2009. Evolutionary history and stress regulation of plant receptor-like kinase/pelle genes. Plant Physiol. 150:12-26.

Lupas, A., Van Dyke, M., and Stock, J. 1991. Predicting coiled coils from protein sequences. Science 252:1162-1164.

Maere, S., Heymans, K., and Kuiper, M. 2005. BiNGO: A Cytoscape plugin to assess overrepresentation of Gene Ontology categories in biological networks. Bioinformatics 21:3448-3449.

Mukhtar, M. S., Carvunis, A.-R., Dreze, M., Epple, P., Steinbrenner, J., Moore, J., Tasan, M., Galli, M., Hao, T., Nishimura, M. T., Pevzner, S. J., Donovan, S. E., Ghamsari, L., Santhanam, B., Romero, V., Poulin, M. M., Gebreab, F., Gutierrez, B. J., Tam, S., Monachello, D., Boxem, M., Harbort, C. J., McDonald, N., Gai, L., Chen, H., He, Y., Vandenhaute, J., Roth, F. P., Hill, D. E., Ecker, J. R., Vidal, M., Beynon, J., Braun, P., and Dangl, J. L. 2011. Independently evolved virulence effectors converge onto hubs in a plant immune system network. Science 333:596-601.

Mur, L. A. J., Kenton, P., Atzorn, R., Miersch, O., and Wasternack, C. 2006. The outcomes of concentration-specific interactions between salicylate and jasmonate signaling include synergy, antagonism, and oxidative stress leading to cell death. Plant Physiol. 140:249-262.

Möckli, N., and Auerbach, D. 2004. Quantitative beta-galactosidase assay suitable for high-throughput applications in the yeast two-hybrid system. Biotechniques 36:872-876.

Ouko, M. O., Sambade, A., Brandner, K., Niehl, A., Peña, E., Ahad, A., Heinlein, M., and Nick, P. 2010. Tobacco mutants with reduced microtubule dynamics are less susceptible to TMV. Plant J. 62:829-839.

Paalme, V., Gammelgård, E., Järvekülg, L., and Valkonen, J. P. T. 2004. In vitro recombinants of two nearly identical potyviral isolates express novel virulence and symptom phenotypes in plants. J. Gen. Virol. 85:739-747.

Peng, Y. H., Kadoury, D., Gal-On, A., Huet, H., Wang, Y., and Raccah, B. 1998. Mutations in the HC-Pro gene of zucchini yellow mosaic potyvirus:effects on aphid transmission and binding to purified virions. J. Gen. Virol. 79:897-904.

Pfaffl, M. W. 2001. A new mathematical model for relative quantification in real-time RT-PCR. Nucl. Acids Res. 29:e45.

Plisson, C., Drucker, M., Blanc, S., German-Retana, S., Le Gall, O., Thomas, D., and Bron, P. 2003. Structural characterization of HC-Pro, a plant virus multifunctional protein. J. Biol. Chem. 278:23753-23761.

Pontier, D., Tronchet, M., Rogowsky, P., Lam, E., and Roby, D. 1998. Activation of hsr203, a plant gene expressed during incompatible plantpathogen interactions, is correlated with programmed cell death. Mol. Plant-Microbe Interact. 11:544-554.

Purcifull, D. E., and Hiebert, E. 1992. Serological relationships involving potyviral nonstructural proteins. Arch. Virol. Suppl 5:97-122.

Puurand, Ü., Valkonen, J. P. T., Mäkinen, K., Rabenstein, F., and Saarma, M. 1996. Infectious in vitro transcripts from cloned cDNA of the potato A potyvirus. Virus Res. 40:135-140.
Qiao, F., Chang, X.-L., and Nick, P. 2010. The cytoskeleton enhances gene expression in the response to the Harpin elicitor in grapevine. J. Exp. Bot. 61:4021-4031.

Rajamäki, M., Merits, A., Rabenstein, F., Andrejeva, J., Paulin, L., Kekarainen, T., Kreuze, J. F., Forster, R. L. S., and Valkonen, J. P. T. 1998. Biological, serological, and molecular differences among isolates of potato a potyvirus. Phytopathology 88:311-321

Rajamäki, M.-L., Mäki-Valkama, T., Mäkinen, K., and Valkonen, J. P. T. 2004. Infection with potyviruses. Pages 68-91 in: Plant-Pathogen Interactions, N. J. Talbot, ed. Blackwell Publishing, Sheffield, U.K.

Reinbothe, S., Mollenhauer, B., and Reinbothe, C. 1994. JIPs and RIPs: The regulation of plant gene expression by jasmonates in response to environmental cues and pathogens. Plant Cell 6:1197-1209.

Roy, A., Kucukural, A., and Zhang, Y. 2010. I-TASSER: A unified platform for automated protein structure and function prediction. Nat. Protoc. 5:725-738.

Ruggenthaler, P., Fichtenbauer, D., Krasensky, J., Jonak, C., and Waigmann, E. 2009. Microtubule-associated protein AtMPB2C plays a role in organization of cortical microtubules, stomata patterning, and tobamovirus infectivity. Plant Physiol. 149:1354-1365.

Ruiz-Ferrer, V., Boskovic, J., Alfonso, C., Rivas, G., Llorca, O., LopezAbella, D., and Lopez-Moya, J. J. 2005. Structural analysis of tobacco etch potyvirus HC-Pro oligomers involved in aphid transmission. J. Virol. 79:3758-3765

Saeed, A. I., Bhagabati, N. K, Braisted, J. C., Liang, W., Sharov, V., Howe, E. A., Li, J., Thiagarajan, M., White, J. A., and Quackenbush, J. 2006. TM4 microarray software suite. Meth. Enzymol. 411:134-193.

Schraudner, M., Moeder, W., Wiese, C., Van Camp, W., Inzé, D., Langebartels, C., and Sandermann, H. Jr. 2001. Ozone-induced oxidative burst in the ozone biomonitor plant, tobacco Bel W3. Plant J. 16:235-245.

Sharan, M., Taguchi, G., Gonda, K., Jouke, T., Shimosaka, M., Hayashida, N., and Okazaki, M. 1998. Effects of methyl jasmonate and elicitor on the activation of phenylalanine ammonia-lyase and the accumulation of scopoletin and scopolin in tobacco cell cultures. Plant Sci. 132:13-19.

Shi, F.-M., Yao, L.-L., Pei, B.-L., Zhou, Q., Li, X.-L., Li, Y., and Li, Y.-Z. 2009. Cortical microtubule as a sensor and target of nitric oxide signal during the defence responses to Verticillium dahliae toxins in Arabidopsis. Plant Cell Environ. 32:428-438.

Shoji, T., Narita, N. N., Hayashi, K., Asada, J., Hamada, T., Sonobe, S. Nakajima, K., and Hashimoto, T. 2004. Plant-specific microtubuleassociated protein SPIRAL2 is required for anisotropic growth in Arabidopsis. Plant Physiol. 136:3933-3944.

Sikorskaite, S., Vuorinen, A. L., Rajamäki, M.-L., Nieminen, A., Gaba, V., and Valkonen, J. P. T. 2010. HandyGun: An improved custom-designed, non-vacuum gene gun suitable for virus inoculation. J. Virol. Methods $165: 320-324$

Smyth, G. K. 2004. Linear models and empirical bayes methods for assessing differential expression in microarray experiments. Stat. Appl. Genet. Mol. Biol. 3:Article3.

Thimm, O., Bläsing, O., Gibon, Y., Nagel, A., Meyer, S., Krüger, P., Selbig, J., Müller, L. A., Rhee, S. Y., and Stitt, M. 2004. MAPMAN: A user-driven tool to display genomics data sets onto diagrams of metabolic pathways and other biological processes. Plant J. 37:914-939.

Torres-Barceló, C., Martín, S., Daròs, J.-A., and Elena, S. F. 2008. From hypo- to hypersuppression: Effect of amino acid substitutions on the RNA-silencing suppressor activity of the tobacco etch potyvirus HCpro. Genetics 180:1039-1049.

Tulin, A., McClerklin, S., Huang, Y., and Dixit, R. 2012. Single-molecule analysis of the microtubule cross-linking protein MAP65-1 reveals a molecular mechanism for contact-angle-dependent microtubule bundling. Biophys. J. 102:802-809.

Urcuqui-Inchima, S., Maia, I. G., Arruda, P., Haenni, A. L., and Bernardi, F. 2000. Deletion mapping of the potyviral helper component-proteinase reveals two regions involved in RNA binding. Virology 268:104111.

Valkonen, J. P. T., Slack, S., Plaisted, R., and Watanabe, K. 1994. Extreme resistance is epistatic to hypersensitive resistance to potato virus $\mathrm{Y}^{\mathrm{o}}$ in a Solanum tuberosum subsp. andigena-derived potato genotype. Plant Dis. 78:1177-1180.

Valkonen, J. P. T., Puurand, U., Slack, S., Mäkinen, K., and Saarma, M. 1995. Three strain groups of potato A potyvirus based on hypersensitive responses in potato, serological properties, and coat protein sequences. Plant Dis. 79:748-753.

Valkonen, J. P. T, Kyle, M. M., and Slack, S. A. 1996. Comparison of resistance to potyviruses within Solanaceae: Infection of potatoes with tobacco etch potyvirus and peppers with potato $\mathrm{A}$ and $\mathrm{Y}$ potyviruses Ann. Appl. Biol. 129:25-38.

Valkonen, J. P. T, Rajamäki, M.-L., and Kekarainen, T. 2002. Mapping of viral genomic regions important in cross-protection between strains of a 
potyvirus. Mol. Plant-Microbe Interact. 15:683-692.

Van Loon, L. C., and Van Strien, E. A. 1999. The families of pathogenesisrelated proteins, their activities, and comparative analysis of PR-1 type proteins. Physiol. Mol. Plant Pathol. 55:85-97.

Volland, C., Urban-Grimal, D., Géraud, G., and Haguenauer-Tsapis, R. 1994. Endocytosis and degradation of the yeast uracil permease under adverse conditions. J. Biol. Chem. 269:9833-9841.

Vuorinen, A. L., Gammelgård, E., Auvinen, P., Somervuo, P., Dere, S., and Valkonen, J. P. T. 2010. Factors underpinning the responsiveness and higher levels of virus resistance realized in potato genotypes carrying virus-specific $R$ genes. Ann. Appl. Biol. 157:229-241.

Watanabe, K., Orrillo, M., Iwanaga, M., Ortiz, R., Freyre, R., and Perez, S. 1994. Diploid potato germplasm derived from wild and land race genetic resources. Am. Potato J. 71:599-604.

Wright, K. M., Cowan, G. H., Lukhovitskaya, N. I., Tilsner, J., Roberts, A. G., Savenkov, E. I., and Torrance, L. 2010. The N-terminal domain of PMTV TGB1 movement protein is required for nucleolar localization, microtubule association, and long-distance movement. Mol. PlantMicrobe Interact. 23:1486-1497.

Yao, L.-L., Zhou, Q., Pei, B.-L., and Li, Y.-Z. 2011. Hydrogen peroxide modulates the dynamic microtubule cytoskeleton during the defence responses to Verticillium dahliae toxins in Arabidopsis. Plant Cell Environ. 34:1586-1598.

Yao, M., Wakamatsu, Y., Itoh, T. J., Shoji, T., and Hashimoto, T. 2008. Arabidopsis SPIRAL2 promotes uninterrupted microtubule growth by suppressing the pause state of microtubule dynamics. J. Cell. Sci.
121:2372-2381.

Ye, C., Dickman, M. B., Whitham, S. A., Payton, M., and Verchot, J. 2011. The unfolded protein response is triggered by a plant viral movement protein. Plant Physiol. 156:741-755.

Zamyatnin, A. A. Jr, Solovyev, A. G., Bozhkov, P. V., Valkonen, J. P. T., Morozov, S. Y., and Savenkov, E. I. 2006. Assessment of the integral membrane protein topology in living cells. Plant J. 46:145-154.

Zhang, J., Liang, Y., and Zhang, Y. 2011. Atomic-level protein structure refinement using fragment-guided molecular dynamics conformation sampling. Structure 19:1784-1795.

Zhang, Y. 2008. I-TASSER server for protein 3 D structure prediction. BMC Bioinformatics 9:40.

Zhang, Y., and Skolnick, J. 2005. TM-align: A protein structure alignment algorithm based on the TM-score. Nucl. Acids Res. 33:2302-2309.

Zilian, E., and Maiss, E. 2011. Detection of plum pox potyviral proteinprotein interactions in planta using an optimized mRFP-based bimolecular fluorescence complementation system. J. Gen. Virol. 92:27112723

\section{AUTHOR-RECOMMENDED INTERNET RESOURCES}

National Center for Biotechnology Information (NCBI)website; www.ncbi.nlm.nih.gov

NCBI Gene Expression Omnibus database: www.ncbi.nlm.nih.gov/geo

SOL Genomics network: solgenomics.net 